\title{
FBG-Based Creep Analysis of GFRP Materials Embedded in Concrete
}

\author{
Guo-Wei Li, ${ }^{1,2}$ Cheng-Yu Hong, ${ }^{3,4}$ Jian Dai, ${ }^{1,5}$ Liang Yu, ${ }^{1,5}$ and Wan-Huan Zhou ${ }^{6}$ \\ ${ }^{1}$ Key Laboratory of Ministry of Education for Geotechnique and Embankment Engineering, Hohai University, Nanjing, Jiangsu, China \\ ${ }^{2}$ Highway and Railway Engineering Institute, Hohai University, Nanjing, Jiangsu, China \\ ${ }^{3}$ Department of Civil Engineering, Shantou University, Shantou, Guangdong, China \\ ${ }^{4}$ State Key Laboratory of Earthquake Dynamics, Institute of Geology, China Earthquake Administration, China \\ ${ }^{5}$ Geotechnical Research Institute, Hohai University, Nanjing, Jiangsu, China \\ ${ }^{6}$ Department of Civil and Environmental Engineering, Faculty of Science and Technology, University of Macau, Macau
}

Correspondence should be addressed to Cheng-Yu Hong; joeyhcy@gmail.com

Received 14 October 2013; Accepted 29 November 2013

Academic Editor: Jun Li

Copyright (C) 2013 Guo-Wei Li et al. This is an open access article distributed under the Creative Commons Attribution License, which permits unrestricted use, distribution, and reproduction in any medium, provided the original work is properly cited.

\begin{abstract}
This paper presents a typical study regarding the creep interaction behavior between prestressed glass fiber reinforced polymer (GFRP) bar and concrete when this GFRP bar is subjected to a constant external pullout force. A number of optical fiber Bragg grating (FBG) sensors were mounted on GFRP bar surface by using an innovative installation method to measure strain distributions. Test results indicate that the complicated interaction at GFRP bar-concrete interface can be evaluated using a transitional factor. Variation trends of this transitional factor indicate three typical zones characterized by different strain/stress variation trends of the GFRP bar when prestress values are sustained at specific levels. These three typical zones include stress release zone, stress transition zone, and continuous tension zone. Test results also suggest that the instant stress loss at the interaction interface between concrete and GFRP bar was quite limited (less than 5\%) in present test. Contributed proportion of each GFRP bar section was obtained to represent the creep behavior of the GFRP bar embedded in concrete. This investigation improved the understanding of the short-term interaction behavior between prestressed GFRP bar and concrete.
\end{abstract}

\section{Introduction}

Fiber reinforced polymer (FRP), as a newly developed composite material, has been widely used for temporary and longterm reinforcement of slopes, excavations, and retaining walls in recent years. The behavior of FRP bar, particularly glass fiber reinforced polymer (GFRP) bar composite material, is quite different from steel bars particularly in the stiffness and strength properties. In several engineering projects, GFRP bar has been accepted for the replacement of common steel bars due to the advantages of high resistance to corrosion under serve environmental conditions, high tensile strength, light weight, and ease of handling during production process. Bond strength at the interface between concrete and FRP bar material is a major concern to researchers and engineers accounted for safety analysis and engineering design. The most common measure to examine the interface strength is pullout (or compression) test, where the stress transferring mechanism can be comprehensively understood by the measurement of force-displacement relationships [1-5]. Some typical sensors such as fiber Bragg grating sensors were found to be very effective for the measurement of particularly small structural deformation [6].

Creep behavior of GFRP bar embedded in concrete is normally investigated in terms of the frictional resistance mobilized at the interaction interface. Typical analytical studies show that the use of a proper mathematical model (or different stress-displacement relationships) to simulate the interface behavior between GFRP bar and concrete is possible [7-9], while the practical interaction behavior is normally complex, depending upon a number of uncertain factors, such as bar types, surface treatment methods, surface degradation, and external temperature changes, $[8,10-13]$. Researchers have made substantial contributions to the safety 


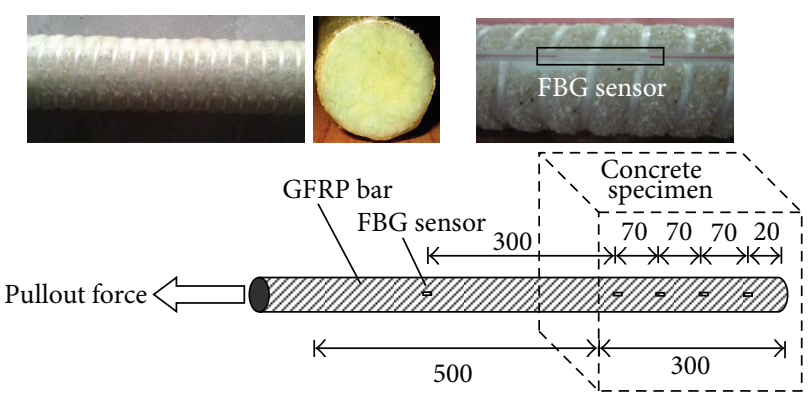

FIGURE 1: Photos of the GFRP bar used in present test and a schematic view of dimensions of test specimens and locations of FBG strain sensors.

analysis of engineering structures reinforced by GFRP bars using mathematical models or from the analysis of practical measurement results $[14,15]$.

Creep behavior between GFRP composite material and concrete is critical and normally examined using pullout tests or compression tests. This interaction process normally requires a time-dependent process $[16,17]$. Long-term or short-time creep behavior is mostly realized by deformation (strain) measurement of FRP reinforced specimens under different loading tests (applied on concrete or FRP material). Sá et al. [7] examined the time-stress relationships of GFRP element subjected to sustained external loads using empirical methods. The effective stiffness reduced nearly $25 \%$ after a measurement period of more than one year. A good agreement between analytical predictions and measurement results is obtained. Sá et al. [18] also found that creepocity measured on fiber reinforced polymer (FRP) materials and pultruded glass fibre reinforced polymers (GFRPs) was quite significant after the first hour in experiment.

Other experimental studies indicate that the behavior of FRP material embedded in concrete is complicated. Ferrier et al. [19] carried out a systematic study on eight concrete specimens which were confined using FRP composite materials, with a new analytical approach proposed to predict the concrete behavior under compression. Major test results from Soong et al. [8] suggest that the maximum pullout force of the GFRP bar consists of debond load, bearing load, and frictional load. The quantified calculation of each force component was derived. Seracino et al. [20] adopted rheological model to predict the strain variation associated with time. The whole test lasted for one year. Creep strain shows significant rise in the first ten days when the concrete specimen was subjected to axial compression. Zhang et al. [21] performed a creep test study on four specimens, which were loaded for 312 days, and then all external loads were released to evaluate the deformation recovery behavior. A modified model was also adopted and the calculated results were used to verify the measurement data. The creep compression tests which lasted for about one year presented by Wang and Zhang [22] show that the creep behavior of the concrete confined by FRP has substantial effect on the elastic modulus and deformation capability. Other experimental studies indicate that the interaction behavior
TABLE 1: Parameter values of test materials.

\begin{tabular}{lcc}
\hline Parameter & Unit & Value \\
\hline Elastic modulus of GFRP bar & $\mathrm{GPa}$ & 50 \\
Ultimate tensile strength of GFRP bar & $\mathrm{MPa}$ & 853 \\
GFRP bar diameter & $\mathrm{mm}$ & 26 \\
Anchorage length of GFRP bar in concrete & $\mathrm{mm}$ & 300 \\
Anchorage length of steel tube & $\mathrm{mm}$ & 400 \\
Length of free part of GFRP bar & $\mathrm{mm}$ & 500 \\
Ratio of water over soundless breaking & - & $0.3: 1$ \\
Curing time of concrete & day & 28 \\
Ultimate compressive strength of concrete & $\mathrm{MPa}$ & 34.5 \\
\hline
\end{tabular}

between concrete and FRP composite material is complex and depends on many uncertain factors, such as temperature level, creep behavior, water condition (tap-water or seawater), and moisture condition (wet or dry) $[13,23,24]$. This paper presents a typical experimental investigation regarding the creep interaction behavior of GFRP bars embedded in concrete and the related stress transfer mechanism during loading process. Basic test setup, an innovative installation method of optical fiber sensors, typical measurement results, and the related test findings are summarized and analyzed for better understanding of the creep interaction behavior at the interface between concrete and GFRP bar.

\section{Materials Properties and Experimental Equipment}

Glass fiber reinforced polymer (GFRP) material was adopted as reinforcement in concrete in present experiment. This composition material consisted of $17.3 \%$ epoxy resin, $75.7 \%$ glass fiber, and $7 \%$ silica. The concrete used in present study consisted of $14.3 \%$ cement, $28.6 \%$ medium sand, $50 \%$ gravel, and $7.1 \%$ water. Figure 1 shows a schematic view of dimensions of test specimen. The GFRP bar was $26 \mathrm{~mm}$ in diameter, $500 \mathrm{~mm}$ in free part length, and $300 \mathrm{~mm}$ in anchorage length in concrete. This dimension is similar to the most common GFRP bars used in practical field. Table 1 summarizes all parameter values of materials used in the present study.

For the measurement of occurred strain along the GFRP bar during loading process, a total of five fiber Bragg grating (FBG) sensors were mounted on the GFRP bar surface with an innovative installation method. Locations of these five FBG sensors (in the anchorage part) were $0,40,110,180$, and $250 \mathrm{~mm}$ away from the GFRP bar head. In comparison with traditional strain sensors (e.g., strain gauge), FBG sensor is more sensitive to the occurred small deformation (the minimum resolution of FBG sensor is less than $10 \mu \varepsilon$ ). This employed installation method of FBG sensors is a key procedure to reflect the real deformation of GFRP bar structures under external load. In this test, a $2 \mathrm{~mm}$ wide, $2 \mathrm{~mm}$ deep, and $15 \mathrm{~mm}$ long slot was created on the GFRP bar surface using an electric saw. The FBG strain sensor part was embedded in this slot carefully and fixed inside at the two ends with instant glue. Epoxy resin was then used to cover the whole sensor part. Normally after 2-3 hours, the FBG sensor could 


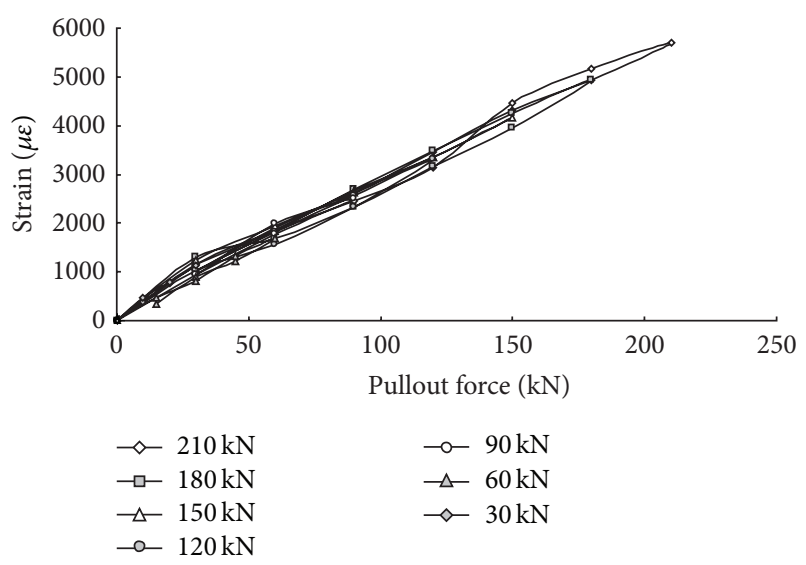

(a) Pullout force $(\mathrm{kN})$

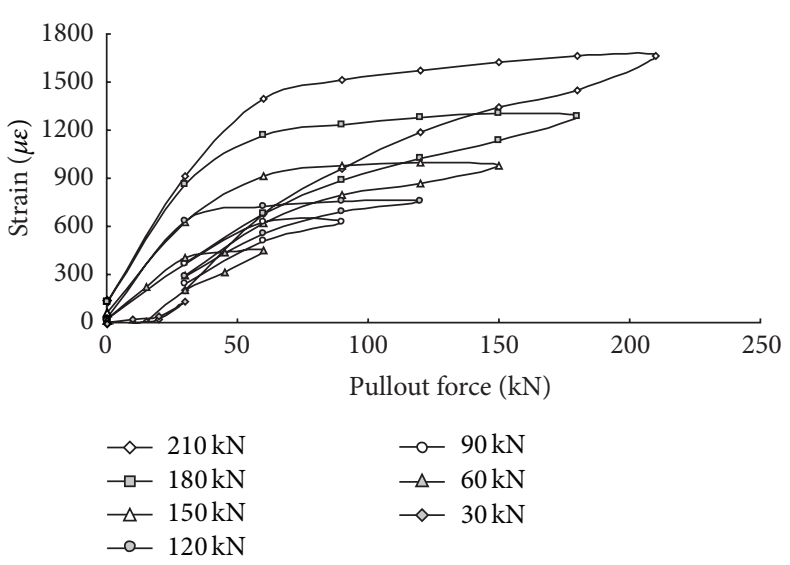

(b) Pullout force $(\mathrm{kN})$

FIGURE 2: Typical relationships of GFRP bar strain against pullout force for the GFRP locations, (a) $40 \mathrm{~mm}$ and (b) $250 \mathrm{~mm}$.

be encapsulated in this slot and used to measure the real strain change. Since FBG sensor is a flexible material and not sensitive to compression, all FBG sensors were maintained in slightly tension effect before placing into slots of GFRP bar surface. Figure 1 (upper part) presents a FBG sensor fully covered with epoxy resin in a slot of the GFRP bar surface. Typical photos of cross-sectional area and length of the GFRP bar are also shown in this figure indicating the exact location of a FBG sensor which reflects the magnitude of optical wavelength shift associated with external deformation and temperature change. The basic linear relationship between FBG sensor and the occurred strain can be found in Hong et al. [2]. Basic setup of pullout test of the GFRP bar embedded in concrete is also presented in Figure 1. For the application of pullout force on the GFRP anchorage bar, a reaction frame was designed and installed on the bar head. A hydraulic jack was used between concrete specimen and stainless steel tube to apply pullout force on the anchorage part, with a load cell in between to measure the applied external load.

\section{Pullout Test}

After the concrete specimen was cured 28 days after grouting, a step loading method was employed on the GFRP bar head to examine the pullout resistance of the GFRP bar and the occurred strain distribution along this GFRP bar. Loading increment was $30 \mathrm{kN}$ and was maintained 10 minutes for each loading step. The ultimate pullout force applied at the GFRP bar head was $210 \mathrm{kN}$. The pullout force was then reduced in a corresponding step by step form (load reduction for each unloading step $=30 \mathrm{kN}$ ). During the whole pullout test process, all load values and strain data were collected by load cell and optical fiber sensors, respectively. The frequency of strain data collection was $10 \mathrm{~Hz}$.

\section{Monitoring Strain Results and Analysis}

As introduced in the previous section, the pullout force was applied step by step. Figures 2(a) and 2(b) show typical measured strain curves against pullout force measured by

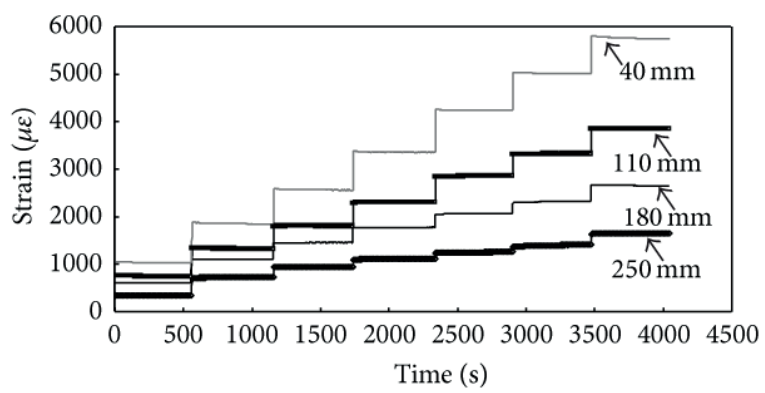

FIGURE 3: Relationships of measured strain of GFRP bar against time at different locations of the GFRP bar.

the optical fiber sensors at the locations 40 and $250 \mathrm{~mm}$ to GFRP bar tip. The maximum tension strain values measured in present test were about $5500 \mu \varepsilon$ at the bar head and about $1600 \mu \varepsilon$ at the location $250 \mathrm{~mm}$ to the GFRP bar head. This indicates that the FBG sensor is capable of identifying very large tension deformation. Figure 3 shows the measured strain distribution against pullout time. All the measured strain values increase in a step by step form, and the measured strain values decrease from GFRP bar head $(40 \mathrm{~mm})$ to the location close to the GFRP bar tip $(250 \mathrm{~mm})$ at different loading levels.

To better understand the transitional interaction behavior between GFRP bar and concrete, all measured strain data after pullout force was maintained at a specified level are summarized in present study. Figures 4(a), 4(b), 4(c), 4(d), and $4(\mathrm{e})$ show the typical strain variation trends against time after a specified pullout force $(210 \mathrm{kN})$ was sustained at the GFRP bar head. All strain data were collected immediately after the pullout force is applied and maintained at the GFRP bar head. It is clear that the strain values show different variation trends against time in all these figures. At the location close to the GFRP bar head, strain values show continuous reductions; for example, reductions of strain values at the locations of 0,40 , and $110 \mathrm{~mm}$ are around 76, 82, and $13 \mu \varepsilon$, respectively as shown in Figures 4(a), 4(b), and 4(c). 


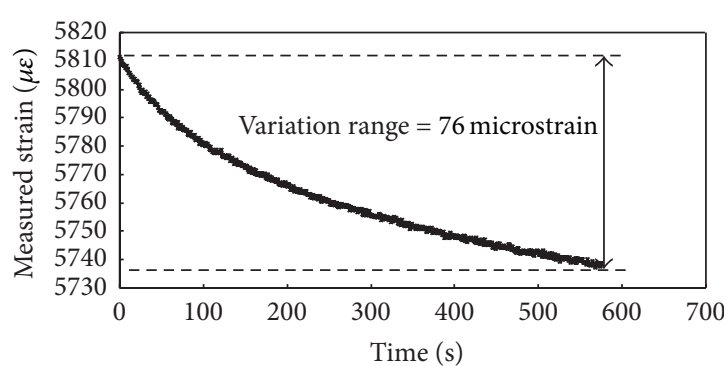

(a) $D=0 \mathrm{~mm}$

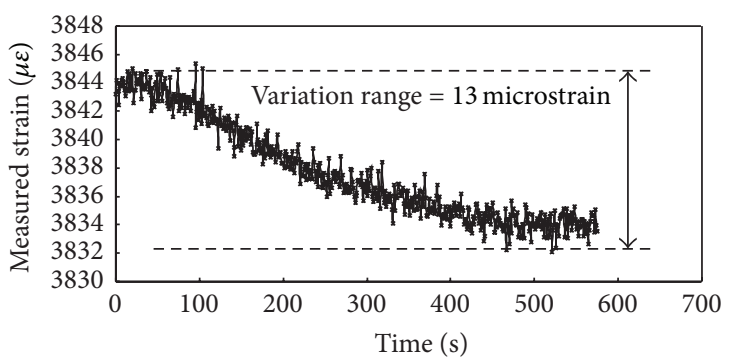

(c) $D=110 \mathrm{~mm}$

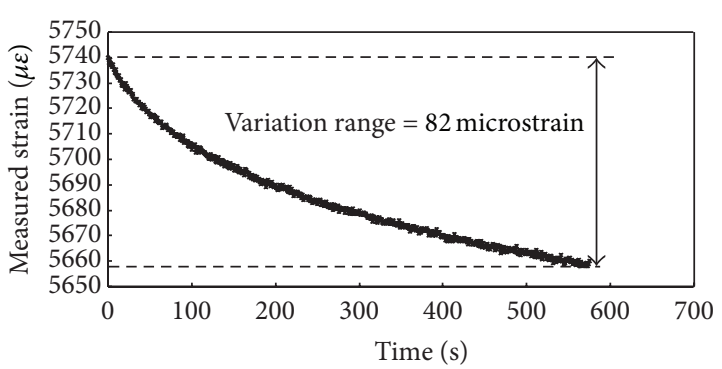

(b) $D=40 \mathrm{~mm}$

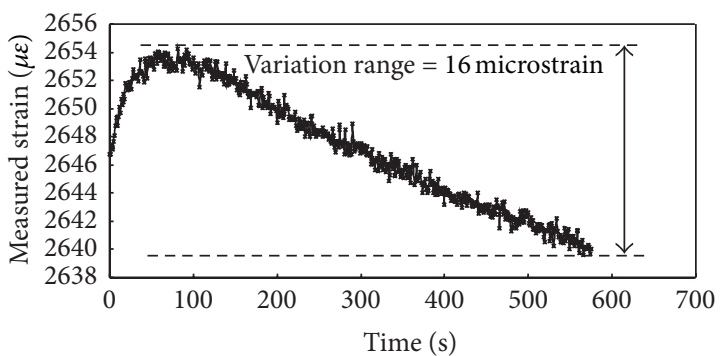

(d) $D=180 \mathrm{~mm}$

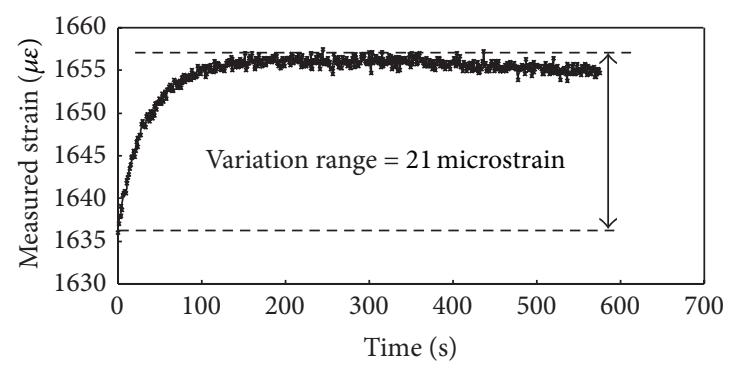

(e) $D=250 \mathrm{~mm}$

Figure 4: Typical measured strain variations against time after the application of $210 \mathrm{kN}$ pullout force at the different distances from the GFRP bar head-(a) $0 \mathrm{~mm}$, (b) $40 \mathrm{~mm}$, (c) $110 \mathrm{~mm}$, (d) $180 \mathrm{~mm}$, and (e) $250 \mathrm{~mm}$.

This suggests that the tension deformation of the GFRP bar relaxes slightly after the pullout force is immediately sustained. This GFRP bar deformation at the location of $180 \mathrm{~mm}$ shows slightly different variation trend compared with the locations near the GFRP bar head as shown in Figure 4(d), where the measured strain values increase first then decrease substantially (maximum reduction is $16 \mu \varepsilon$ ). Why? Immediately after the application of pullout force, the GFRP bar head would react first; then, a relevant tension deformation takes place at the bar head and starts to transfer long the longitudinal direction. At the deeper location like $180 \mathrm{~mm}$ in Figure 4(d), pullout force requires a process to transfer and achieve this location, so that the measured strain increases first (due to the reaction of the GFRP bar to pullout force) and deformation relaxes progressively (strain release). Figure 4(e) also verifies this observation; that is, the initial strain values increase substantially but show slight reductions afterwards. The optical fiber sensors used in present test show a relative high resolution and successfully identify very small strain values (less than $10 \mu \varepsilon$ ).

\section{Transitional Interaction Behavior between GFRP Bar and Concrete}

Significant pullout force may result in debonding condition and damage the initial bonding state between GFRP bar and concrete. It is therefore crucial to understand the real strain/stress transfer process during and after the application of pullout force. From the measured strain results shown in Figures 4(a)-4(e), three typical interaction states can be obtained including consistent rise, obvious rise followed by a reduction, and continuous reduction of tension strain values. To better identify these three typical variation trends, a normalized parameter, namely, transitional factor $\lambda_{T}$, is proposed to represent these strain/stress development states of the GFRP bar as follows:

$$
\lambda_{T}=\frac{\varepsilon_{i}-\varepsilon_{\min }}{\varepsilon_{\max }-\varepsilon_{\min }},
$$

where $\varepsilon_{i}, \varepsilon_{\max }$, and $\varepsilon_{\min }$ are present, maximum, and minimum strain values during the sustaining process of pullout force 


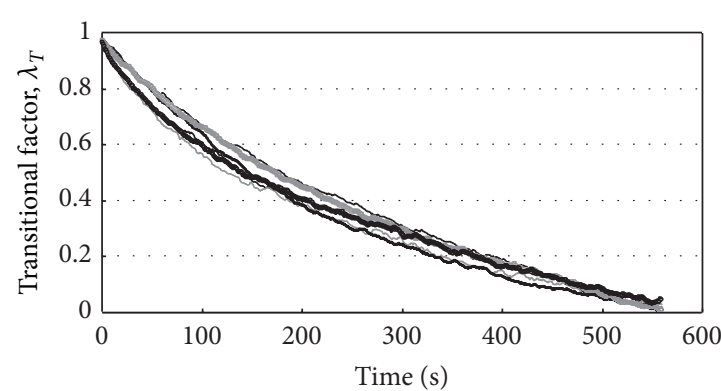

(a) $0 \mathrm{~mm}$

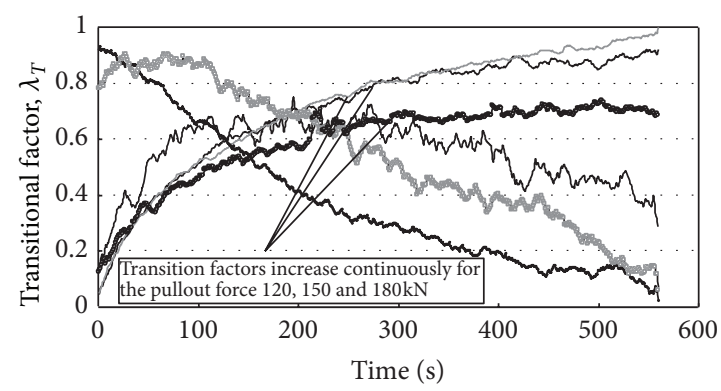

(c) $110 \mathrm{~mm}$

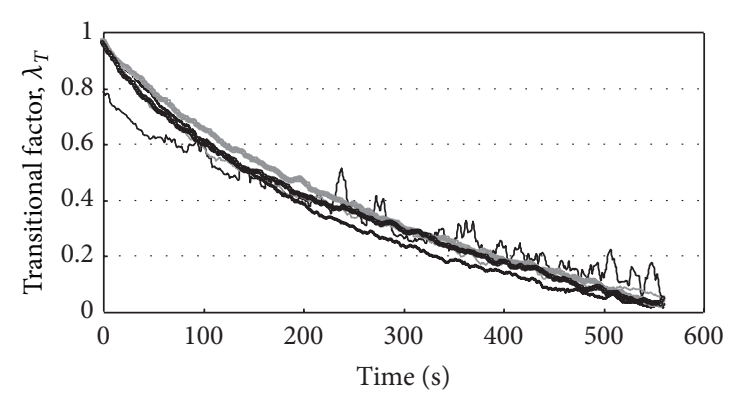

(b) $40 \mathrm{~mm}$

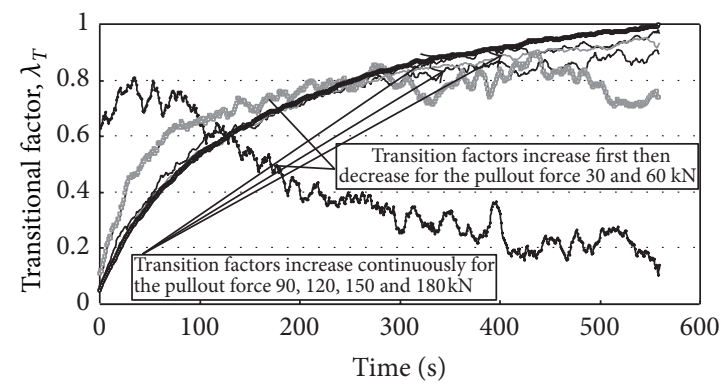

(d) $180 \mathrm{~mm}$

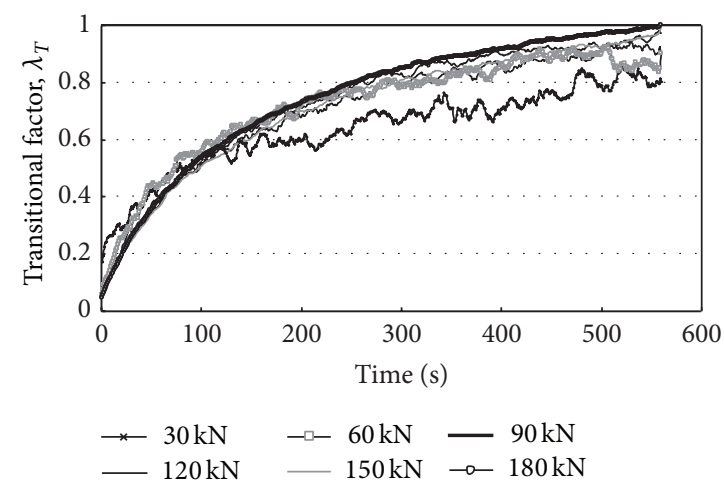

(e) $250 \mathrm{~mm}$

Figure 5: Relationships of transitional factor variations against time at different sensor distances from bar head, (a) $0 \mathrm{~mm}$, (b) $40 \mathrm{~mm}$, (c) $110 \mathrm{~mm}$, (d) $180 \mathrm{~mm}$, and (e) $250 \mathrm{~mm}$.

at the GFRP bar head. As $\left(\varepsilon_{\max }-\varepsilon_{\min }\right)$ is a constant value for a specified pullout process, and $\left(\varepsilon_{\max } \geq \varepsilon_{i} \geq \varepsilon_{\min }\right)$ always hold, so that $0 \leq \lambda_{T} \leq 1$. This proposed transitional factor $\lambda_{T}$ is a normalized factor, providing a basic evaluation of stress transition behavior (stress release or concentration) at various loading processes. A continuous increase (decrease) of $\lambda_{T}$ value indicates a continuous development (release) of tension strain. It is noted that the normalized transitional factor $\lambda_{T}$ is time-dependent and may vary substantially as time elapses.

Figures 5(a)-5(e) summarize changes of all $\lambda_{T}$ values at different GFRP bar locations (bar head, 40, 110, 180, and $250 \mathrm{~mm}$ to bar head) against time under different pullout force values. To clearly identify variation trends of this parameter, average values of $\lambda_{T}$ are obtained in these figures (calculated by averaging every ten strain values). For the strain sensors at the GFRP bar head and $40 \mathrm{~mm}$ to the bar head ( $0 \mathrm{~mm}$ and $40 \mathrm{~mm}$ as marked in Figures 5(a) and 5(b)), the $\lambda_{T}$ values show continuous reductions. This indicates an immediate and consistent strain release effect occurred at both the two locations. In addition, the change of pullout force seems to have limited effect on the variation trends of $\lambda_{T}$ values against time at bar head (Figures 5(a) and 5(b)). This may be interpreted as that, as a result of the pullout force at the bar head, the external load can be easily transferred into deeper locations close to GFRP bar head, leading to an substantial stress release effect immediately after the pullout load is maintained at the bar head.

In comparison with Figures 5(a) and 5(b), variation trends of transitional factors against time are totally different as shown in Figures 5(c), 5(d), and 5(e). A number of consistent increasing curves (e.g., at 120,150 and $180 \mathrm{kN}$ in Figure 5(c); at 90, 120, 150, and $180 \mathrm{kN}$ in Figure 5(d)), or increasing trends followed by an immediate decreasing 
trends (e.g., at 30, 60, and $90 \mathrm{kN}$ in Figure 5(c), 30 and $60 \mathrm{kN}$ in Figure 5(d)), and consistent increasing trends are found (e.g., at all loading levels in Figure 5(e)). These continuous increasing trends of $\lambda_{T}$ values suggest that, though pullout force values no longer increase at the bar head, the related mobilized tension effect still exists at certain depth of the GFRP bar. This tension effect along GFRP bar is transitional and normally requires a time consuming process (though the required time of this process may be quite limited). Continuous increasing trends of transitional factor normally present at high pullout force values $(120,150$, and $180 \mathrm{kN}$ in Figure 5(c); 90, 120, 150, and $180 \mathrm{kN}$ in Figure 5(d)). The calculated transitional factor $\lambda_{T}$ becomes weaker and weaker and finally decreases with time at low pullout force values $(30 \mathrm{kN}$ and $60 \mathrm{kN}$ in Figure 5(c) and $30 \mathrm{kN}$ in Figure 5(d)). Main reason of this finding is that the high pullout force (e.g., $180 \mathrm{kN}$ ) leads to significant tension effect, and this tension effect is relatively strong and results in a corresponding highly transferring effect of strain/stress into deeper locations. All $\lambda_{T}$ variation curves in Figure 5(e) show continuous and substantial rise at $250 \mathrm{~mm}$ from GFRP bar head, which is also the deepest location among all sensors. The pullout effect at this location is the weakest. but the transferring effect requires a long time to approach the maximum tension strain, so that the tension strain values remain increase.

To summarize, from all observations in Figures 4(a)4(e) and Figures 5(a)-5(e), the interaction interface during pullout can be divided into three typical zones. Zone (a) is the location where tension deformation relaxes after the application of pullout force (corresponds to Figures 4(a)-4(c) and Figures 5(a) and 5(b)). This is mainly due to the stress release process at the GFRP bar head or stress redistribution along the GFRP bar. Zone (b) is the GFRP bar location where transition part (between the process of strain release and the mobilization of tension effect) presents and passes (Figures 4(d), 5(c), and 5(d)); that is, the occurred strain values increase first then decrease after the maximum tension strain is approached. Zone (c) is the location where the interface between concrete and GFRP bar is still subjected to tension effect. This is the case that the pullout effect at the GFRP bar head requires a process to transfer and achieve the bar tip (Figures 4(e) and 5(e)). All these three zones are timedependent and can be transferred to each other after pullout force is sustained at the GFRP bar head.

As found from the previous section, the pullout deformation requires a process to approach the location close to the GFRP bar tip. The evaluation of this transitional process is critical for the understanding of the mechanical behavior of structures reinforced by GFRP composite materials. In the present study, a new factor, namely, normalized transitional time factor $N_{T}$, is defined to quantify the transitional behavior of the GFRP bar in concrete as follows:

$$
N_{T}=\frac{T_{\max }}{\Delta T},
$$

where $T_{\max }$ refers to the time interval required for a specified GFRP bar location to approach the maximum tension strain. $\Delta T$ is the total measurement time which may vary significantly for different measurement tests and depends on

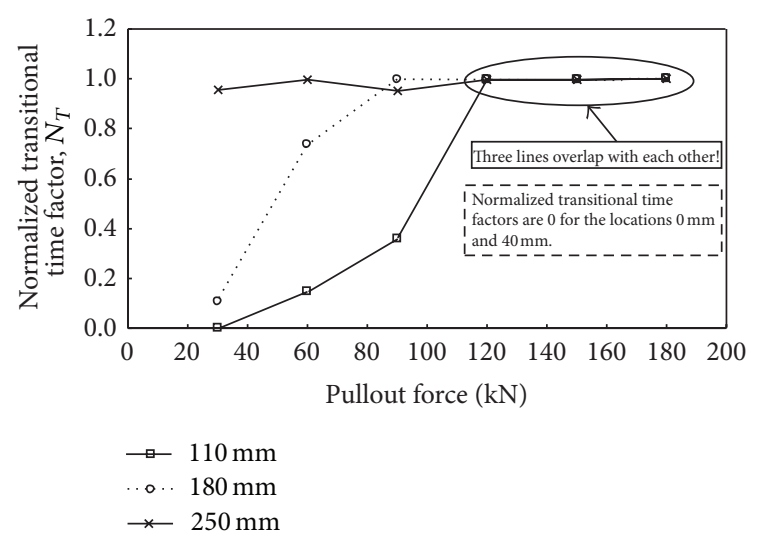

FIGURE 6: Relationships of normalized transitional time factor against pullout force at different locations of the GFRP bar.

the exact measurement time in different tests. For example, the measurement time for long-term and short-term tests varies significantly. In addition, this factor $N_{T}$ can be extended for assessing the transitional behavior of different structures, for example, soil nails, anchor bars, and so forth. A high $N_{T}$ value indicates a related long time required mobilizing the maximum tension strain, and this may be suitable for the case where long GFRP bars are used in concrete structures.

The calculated results of normalized transitional time factor are summarized against time in Figure 6. Only three typical cases are considered, that is, the locations of 110, 180 , and $250 \mathrm{~mm}$ to the GFRP bar tip, and as for other two locations ( 0 and $40 \mathrm{~mm}$ ), the related $N_{T}$ values are all zero. That is, the maximum tension strain is approached immediately after pullout force is sustained at the GFRP bar head. It is clear from Figure 6 that $N_{T}$ value increases from 0 at pullout force of $30 \mathrm{kN}$ to almost 1.0 at the pullout force $120 \mathrm{kN}$ and remains a constant value as pullout force further develops (from 120 to $180 \mathrm{kN}$ ). While for the sensor location $180 \mathrm{~mm}, N_{T}$ value increases initially as well but approaches a constant value at the pullout force of $90 \mathrm{kN}$, which is lower than that at the location of $110 \mathrm{~mm}$. All $N_{T}$ values almost approach a constant value at sensor location $250 \mathrm{~mm}$, indicating that the maximum tension effect remains to develop during the whole testing process. The initial low $N_{T}$ value indicates that the smaller the sensor distance to GFRP bar head, the lower the $N_{T}$ value, as well as the slower the mobilization of the maximum tension strain particularly at high pullout force levels. The increase of pullout force or the reduction of the sensor distance to the GFRP bar head contributes to a high $N_{T}$ value (or a relatively long time to mobilize the maximum tension strain).

\section{Stress Redistribution of GFRP Bar Subjected to Pullout Force}

Stress loss would occur after the application of pullout force. Two typical processes of stress loss may be involved, such as instantaneous loss and long-term time-dependent loss. 
The instantaneous loss of stress may be due to elastic shortening and stress release of the reaction frame, and so forth, while the long-term time-dependent loss of stress may be a result of creep, shrinkage, and release problems associated with the interaction behavior between concrete and GFRP materials. In order to simulate the process of instant stress loss, only the strain data ten minutes after the sustaining process of pullout force at the GFRP bar head were selected in analysis. It is noted that the selection of ten minutes may not be long enough for assessing initial stress loss, but the present consideration is only an example, which may be a typical reference for practical consideration and also a comparison with more data to be collected in further tests. The stress loss coefficient $\mu$ is obtained by dividing the minimum axial stress/strain by the maximum axial stress/strain as follows:

$$
\mu=\frac{\varepsilon_{\min }}{\varepsilon_{\max }}
$$

where $\varepsilon_{\min }$ and $\varepsilon_{\max }$ are minimum and maximum axial strain values that resulted from pullout force, respectively. It is noted that bending effect of GFRP bar in pullout test is ignored in this study.

Figure 7 shows relationships of average stress loss against pullout force at different GFRP bar locations. It is clear the proportion of stress loss decreases as the increase of pullout force, and all percentages of stress loss are extremely limited (lower than 4\%). As the increase of pullout force, the mobilized axial force (or strain) increases as well, but the proportion of axial stress loss at high pullout force levels shows relatively minor reductions; that is, the pullout force increases much faster than the increasing rate of the corresponding stress loss, though the stress loss that occurred at low loading levels is not as significant as that at high loading levels. Variation trend of average percentage of stress loss shows a similar variation trend, with an average percentage loss of stress which reduces from 2.2\% (bar head) to about $1.5 \%$ (bar tip). All percentages of stress loss are very limited in the short-term period after the pullout force is sustained.

\section{Contribution of Pullout Resistance of Each GFRP Bar Section}

The interface between GFRP bar and concrete contributes frictional resistance which is equal to the pullout force applied at the GFRP bar head. The investigation of the pullout resistance contribution from different GFRP bar sections is useful for understanding the interaction mechanism (particularly the transitional interaction behavior) between GFRP bar and concrete. In this study, the GFRP bar is divided into four sections by optical fiber strain sensors. Each bar section contributes certain frictional resistance. From obtained strain results, the corresponding axial force distribution along the GFRP bar can be determined using the following relationship:

$$
p_{i}=A E \varepsilon_{i},
$$

where $p_{i}$ is the axial force $(i=1,2,3,4), A$ and $E$ are the crosssectional area and the GFRP bar modulus, and $\varepsilon_{i}$ denotes

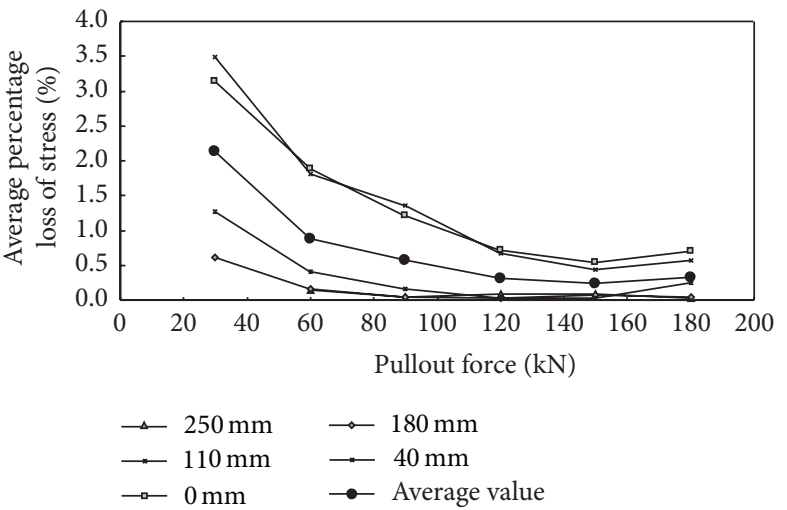

FIGURE 7: Relationships of percentage loss of prestress against pullout force at different sensor locations.

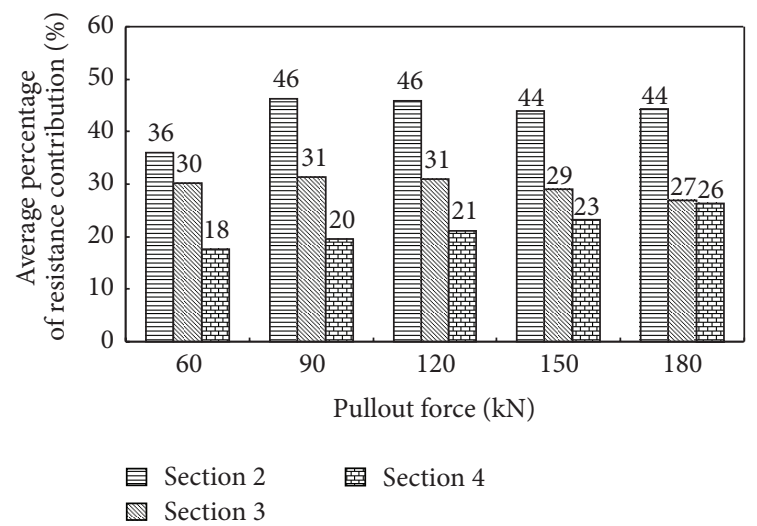

FIGURE 8: Average contribution of pullout resistance of different GFRP bar sections.

the measured strain. The axial force difference at the two ends of each bar section is also the frictional resistance and can be calculated as follows if the measured two point strain values $\varepsilon_{i}$ and $\varepsilon_{i-1}$ are known:

$$
p_{i}-p_{i-1}=A E \varepsilon_{i}-A E \varepsilon_{i-1} .
$$

The total (or applied) pullout force of the GFRP bar head is $p_{1}$, which can be obtained using the strain $\varepsilon_{1}$ measured at the GFRP bar head, so that the contributed percentage of each GFRP bar section is written as follows:

$$
\delta_{i}=\frac{p_{i}-p_{i-1}}{p_{1}-p_{4}}=\frac{A E\left(\varepsilon_{i}-\varepsilon_{i-1}\right)}{A E\left(\varepsilon_{1}-\varepsilon_{4}\right)}=\frac{\varepsilon_{i}-\varepsilon_{i-1}}{\varepsilon_{1}-\varepsilon_{4}},
$$

where $\delta_{i}$ is the contributed proportion of pullout resistance of each GFRP bar section $i(i=1,2,3,4)$. $p_{4}$ is the calculated axial force $(50 \mathrm{~mm})$ close to the GFRP bar tip. Equation (6) indicates that the contributed percentage of all GFRP bar sections can be examined using all strain sensor readings.

The contribution of frictional resistance from different GFRP bar sections is calculated and summarized in Figure 8, where the average percentage of frictional resistance contributions of different sections (Section 2 to Section 4 from GFRP bar head to tip divided by four FBG sensors inside 
concrete) is obtained by using (6). Section 2 is the bar part close to the loading position. At relatively low loading levels, for example, $60 \mathrm{kN}$, the contributed percentage of frictional resistance of Section 2 (closest to the GFRP bar head) is 36\%, which is higher than that of Section 3 (30\%) and Section $4(18 \%)$. Because of the increase of the pullout load, the contributed proportion of frictional resistance of Section 2 is around $44 \%$, while the contributions of the last two sections (Sections 3 and 4) become closer and closer. The contributed percentage of frictional resistance changes from 30\% for Section 3 and $18 \%$ for Section 4 at the load of $60 \mathrm{kN}$ to $27 \%$ for Section 3 and $26 \%$ for Section 4 at the load of $180 \mathrm{kN}$. This is also a result of the load transferring effect from GFRP bar head to the bar tip.

\section{Conclusions}

A typical study regarding the creep analysis of GFRP bar embedded in concrete is presented with the focus on the GFRP bar behavior after the pullout force is sustained at a specific level. Based on a comprehensive and quantified analysis, transitional stress transfer state at the interface between GFRP bar and concrete and stress contributions of different GFRP bar sections are presented and analyzed to better understand the interaction characteristics of GFRP bar. Conclusions and typical findings are summarized as follows.

(1) The measured strain values after the pullout force is sustained at a specific level show continuous increase, or increase first then decrease, or decrease continuously as time elapses. The interface between concrete and GFRP bar may be divided into three typical zones characterized by the above different strain variation trends, including the stress release part, the stress transferring part, and the part subjected to continuous tension effect.

(2) A normalized transitional factor $\lambda_{T}$ is proposed to identify the strain/stress development state of the GFRP bar. The three typical variation trends of $\lambda_{T}$ value, continuous rise or reduction, or rise first followed by typical reduction indicate three corresponding stress transferring states, that is, a continuous development of tension deformation, a continuous release of tension stress, and a presence of stress transitional zone.

(3) The proportion of stress loss decreases as the increase of pullout force, and all percentages of stress loss are extremely limited (lower than 4\%). As the mobilized axial force (or strain) increases, the proportion of axial stress loss at high pullout force levels shows relative reductions. All percentages of stress loss are very limited in the short-term period after the pullout force is sustained at a constant level.

(4) Contributed percentage of frictional resistance of GFRP bar decreases from bar head to bar tip at constant pullout load. As the pullout load becomes higher and higher, the contribution proportions of frictional resistance for the two bar sections in the deeper locations become closer and closer. This is due to the load transferring effect along the GFRP bar.

\section{Acknowledgments}

The authors wish to thank the financial supports from the government of Guangdong Province and Ministry of education of China (Project no. 2009B09060011), STU Scientific Research Foundation for Talents (SRFT) (Project no. NTF12015), and State Key Laboratory of Earthquake Dynamics Institute of Geology, China Earthquake Administration (Project, no. LED2013B01). This work is also supported by the Macau Science and Technology Development Fund (Grant no. FDCT/011/2013/A1) and the University of Macau Research Fund (Grant nos. MYRG189(Y2-L3)-FST11-ZWH and MYRG067(Y2-L2)-FST12-ZWH). The help and support from the technical staff of the Rock and Soil Mechanics Laboratory in the College of Civil and Transportation Engineering of Hohai University are also acknowledged.

\section{References}

[1] L. Chu and J. Yin, "Comparison of interface shear strength of soil nails measured by both direct shear box tests and pullout tests," Journal of Geotechnical and Geoenvironmental Engineering, vol. 131, no. 9, pp. 1097-1107, 2005.

[2] C. Hong, J. Yin, W. Jin, C. Wang, W. Zhou, and H. Zhu, "Comparative study on the elongation measurement of a soil nail using optical lower coherence interferometry method and FBG method," Advances in Structural Engineering, vol. 13, no. 2, pp. 309-319, 2010.

[3] W. Zhou, J. Yin, and C. Hong, "Finite element modelling of pullout testing on a soil nail in a pullout box under different overburden and grouting pressures," Canadian Geotechnical Journal, vol. 48, no. 4, pp. 557-567, 2011.

[4] N. Gurung, "A theoretical model for anchored geosynthetics in pull-out tests," Geosynthetics International, vol. 7, no. 3, pp. 269284, 2000.

[5] K. C. Yeo and S. K. Leung, "Soil nail design with respect to Hong Kong conditions," Landmarks in Earth Reinforcement, vol. 1, pp. 759-764, 2001.

[6] H. F. Pei, J. H. Yin, H. H. Zhu, and C. Y. Hong, "Performance monitoring of a glass fiber-reinforced polymer bar soil nail during laboratory pullout test using fbg sensing technology," International Journal of Geomechanics, vol. 13, no. 4, pp. 467472, 2013.

[7] M. F. Sá, A. M. Gomes, J. R. Correia, and N. Silvestre, "Creep behavior of pultruded GFRP elements, part 2: analytical study," Composite Structures, vol. 93, no. 9, pp. 2409-2418, 2011.

[8] W. H. Soong, J. Raghavan, and S. H. Rizkalla, "Fundamental mechanisms of bonding of glass fiber reinforced polymer reinforcement to concrete," Construction and Building Materials, vol. 25, no. 6, pp. 2813-2821, 2011.

[9] L. Vasseur, S. Matthys, and L. Taerwe, "An analytical study on the bond behaviour between an externally bonded FRP and concrete in the case of continuous beams," Mechanics of Composite Materials, vol. 44, no. 3, pp. 269-278, 2008.

[10] M. Esfandeh, A. R. Sabet, A. M. Rezadoust, and M. B. Alavi, "Bond performance of FRP rebars with various surface deformations in reinforced concrete," Polymer Composites, vol. 30, no. 5, pp. 576-582, 2009. 
[11] H. Ko and Y. Sato, "Bond stress-slip relationship between FRP sheet and concrete under cyclic load," Journal of Composites for Construction, vol. 11, no. 4, pp. 419-426, 2007.

[12] H. Toutanji, P. Saxena, L. Zhao, and T. Ooi, "Prediction of interfacial bond failure of FRP-concrete surface," Journal of Composites for Construction, vol. 11, no. 4, pp. 427-436, 2007.

[13] J.-F. Berthet, E. Ferrier, P. Hamelin, G. Al Chami, M. Thériault, and K. W. Neale, "Modelling of the creep behavior of FRPconfined short concrete columns under compressive loading," Materials and Structures/Materiaux et Constructions, vol. 39, no. 285, pp. 53-62, 2006.

[14] Y. Q. Ni, X. W. Ye, and J. M. Ko, "Monitoring-based fatigue reliability assessment of steel bridges: analytical model and application," Journal of Structural Engineering, vol. 136, no. 12, pp. 1563-1573, 2010.

[15] Y. Q. Ni, X. W. Ye, and J. M. Ko, "Modeling of stress spectrum using long-term monitoring data and finite mixture distributions," Journal of Engineering Mechanics, vol. 138, no. 2, pp. 175183, 2011.

[16] C. Hong, J. Yin, W. Zhou, and H. Pei, "Analytical study on progressive pullout behavior of a soil nail," Journal of Geotechnical and Geoenvironmental Engineering, vol. 138, no. 4, pp. 500-507, 2012.

[17] W. H. Zhou and J. H. Yin, "A simple mathematical model for soil nail and soil interaction analysis," Computers and Geotechnics, vol. 35, no. 3, pp. 479-488, 2008.

[18] M. F. Sá, A. M. Gomes, J. R. Correia, and N. Silvestre, "Creep behavior of pultruded GFRP elements, part 1: literature review and experimental study," Composite Structures, vol. 93, no. 10, pp. 2450-2459, 2011.

[19] E. Ferrier, L. Michel, B. Jurkiewiez, and P. Hamelin, "Creep behavior of adhesives used for external FRP strengthening of RC structures," Construction and Building Materials, vol. 25, no. 2, pp. 461-467, 2011.

[20] R. Seracino, N. M. Jones, M. S. M. Ali, M. W. Page, and D. J. Oehlers, "Bond strength of near-surface mounted FRP strip-toconcrete joints," Journal of Composites for Construction, vol. 11, no. 4, pp. 401-409, 2007.

[21] D. J. Zhang, Y. F. Wang, and Y. S. Ma, "Compressive behaviour of FRP-confined square concrete columns after creep," Engineering Structures, vol. 32, no. 8, pp. 1957-1963, 2010.

[22] Y. Wang and D. Zhang, "Creep-effect on mechanical behavior of concrete confined by FRP under axial compression," Journal of Engineering Mechanics, vol. 135, no. 11, pp. 1315-1322, 2009.

[23] C. M. L. Tavares, M. C. S. Ribeiro, A. J. M. Ferreira, and R. M. Guedes, "Creep behaviour of FRP-reinforced polymer concrete," Composite Structures, vol. 57, no. 1-4, pp. 47-51, 2002.

[24] J. Dai, H. Yokota, M. Iwanami, and E. Kato, "Experimental investigation of the influence of moisture on the bond behavior of FRP to concrete interfaces," Journal of Composites for Construction, vol. 14, no. 6, pp. 834-844, 2010. 


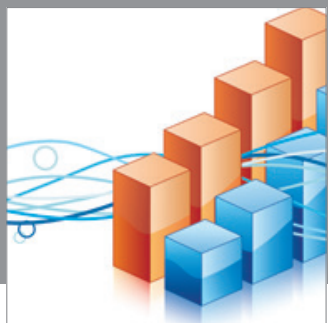

Advances in

Operations Research

mansans

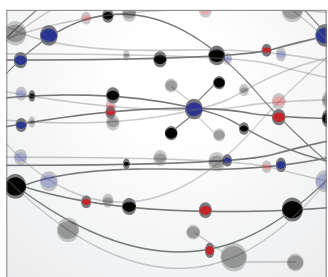

The Scientific World Journal
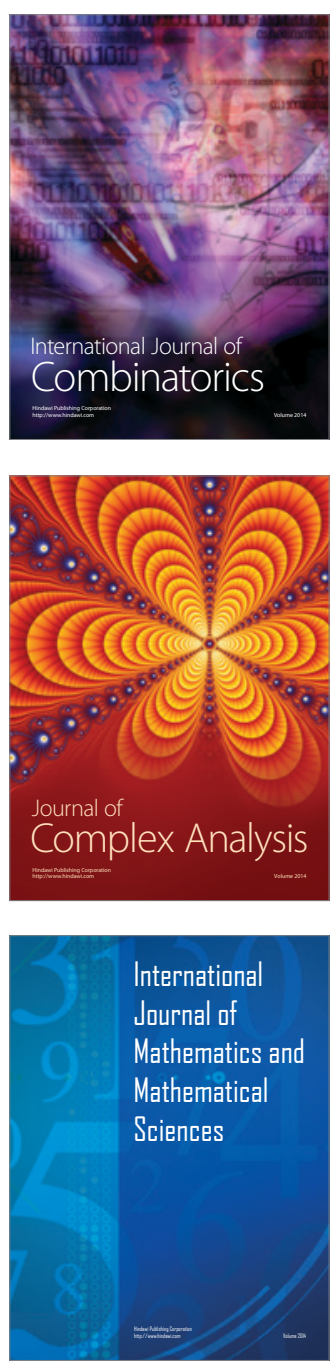
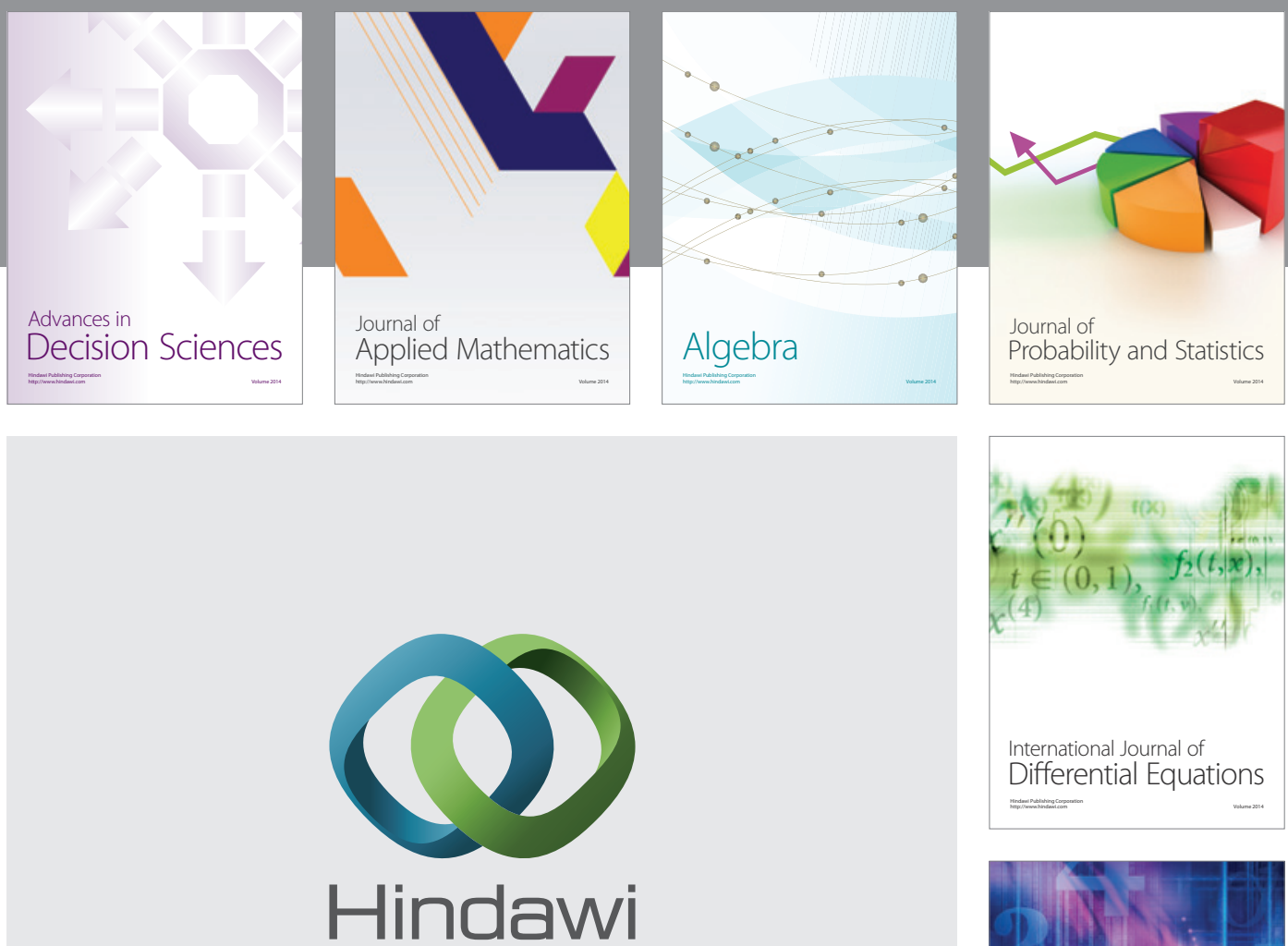

Submit your manuscripts at http://www.hindawi.com
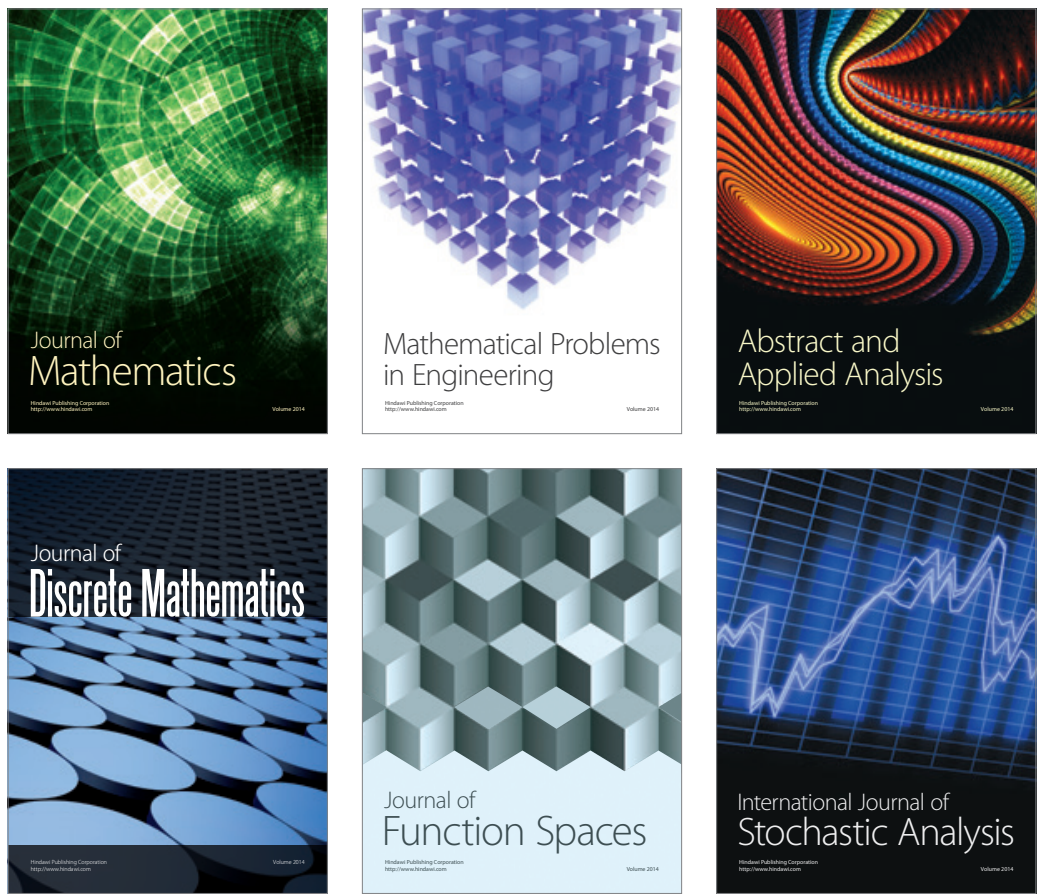

Journal of

Function Spaces

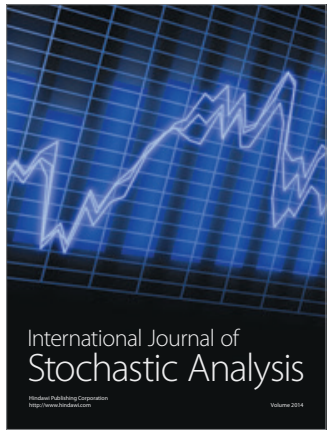

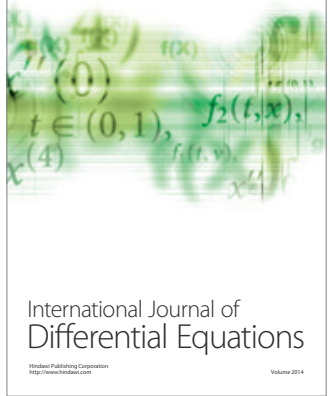
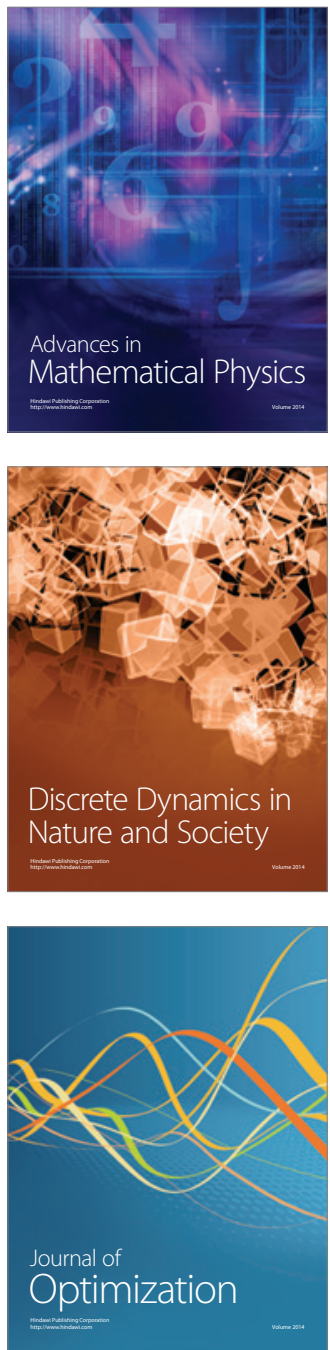